\title{
Ações de educação em saúde sobre parasitoses humanas em escolas públicas no município de Jataí, Goiás
}

Health education actions about human parasitosis in public schools in the municipality of Jataí, State of Goiás, Brazil

\author{
Ivanildes Solange da Costa Barcelos ${ }^{1}$ \\ Letícia Freitas de Almeida ${ }^{2}$ \\ Andrielle Araújo Oliveira ${ }^{3}$ \\ Rosângela Maria Rodrigues ${ }^{4}$
}

\section{RESUMO}

Relato de experiência decorrente do projeto de extensão "Educação em saúde: parasitoses humanas" em escolas públicas no Município de Jataí, Goiás; desenvolvido por docentes e discentes da Universidade Federal de Goiás, Regional Jataí. Esse projeto teve como objetivo realizar ações educativas para estudantes de escolas públicas sobre parasitoses intestinais, pediculose, toxoplasmose e tricomoníase com foco na prevenção e controle de doenças parasitárias. As atividades atenderam 593 crianças e jovens matriculados em creche, ensino fundamental e médio, de nove escolas públicas; selecionadas mediante sorteio e anuência das secretarias municipal e estadual de educação. As palestras, cartazes, jogo de memória, exibição de filmes e teatro de fantoches foram planejadas nas dependências da universidade e executadas nas escolas públicas selecionadas. As ações desenvolvidas foram avaliadas positivamente pelos diretores das escolas e propiciaram interações entre os graduandos e o público-alvo, colaborando na formação de cidadãos mais conscientes da realidade social onde estão inseridos. Além de contribuir na capacitação de biomédicos e enfermeiros comprometidos com a responsabilidade social.

Palavras-chave: Educação em saúde. Doenças parasitárias. Socialização do conhecimento.

\begin{abstract}
Experience report resulting from the extension project "Health education: human parasites" in public schools in the city of Jataí, southwest of the State of Goiás; it was developed by teachers and students of the Federal University of Goiás, Jataí Regional (UFG-REJ), Brazil. The objectives of this project were to carry out educational actions to students of public schools about intestinal parasites, pediculosis, toxoplasmosis and trichomoniasis with focus in the prevention and control of parasitosis. The activities attended 593 children and young people enrolled in nursery, elementary and high school, in nine public schools selected by lottery and consent of the municipal and state Education Secretaries. The actions of lectures,

\footnotetext{
${ }^{1}$ Doutora em Imunologia e Parasitologia Aplicadas pela Universidade Federal de Uberlândia, Minas Gerais, Brasil; professora associada da Universidade Federal de Goiás, Regional Jataí, Brasil. (solbarcelos1@hotmail.com).

2 Graduanda em Biomedicina na Universidade Federal de Goiás, Regional Jataí, Brasil (leticiafreitasjti@gmail.com).

${ }^{3}$ Mestre em Biologia Celular e Estrutural Aplicadas pela Universidade Federal de Uberlândia, Minas Gerais, Brasil (an_dri_k@hotmail.com).

${ }^{4}$ Doutora em Imunologia e Parasitologia Aplicadas pela Universidade Federal de Uberlândia, Minas Gerais, Brasil; professora associada da Universidade Federal de Goiás, Regional Jataí, Brasil; coordenadora geral da Rede Goiana de Pesquisa em Doenças Infecciosas e Parasitárias do Sudoeste (FAPEG), Goiás, Brasil (rosismaria@yahoo.com.br).
} 
posters, memory games, movies exhibitions and puppet theaters were planned at university facilities and performed in selected public schools. The actions developed were positively evaluated by the school principals and provided interactions between the undergraduates and the target audience, contributing to the formation of citizens more aware of the social reality in which they operate. In addition to contributing to the training of biomedical and nurses committed to social responsibility.

Keywords: Health education. Parasitic diseases. Socialization of knowledge.

\section{INTRODUÇÃO}

A Cúpula do Milênio promovida pela Organização das Nações Unidas (ONU), no ano 2000, estabeleceu oito metas com o objetivo de promover a melhoria da saúde e da qualidade de vida da população mundial: 1) Erradicar a extrema pobreza e a fome, 2) Atingir o ensino básico universal, 3) Promover a igualdade entre os sexos e a autonomia das mulheres, 4) Reduzir a mortalidade infantil, 6) Combater o HIV/Aids, a malária e outras doenças, 7) Garantir a sustentabilidade ambiental e 8) Estabelecer uma parceria mundial para o desenvolvimento (ONU, 2015). Dentre essas, as metas 4 e 6 motivaram a implementação do presente projeto de extensão, pois, dentre as medidas para reduzir a mortalidade infantil e de combate as doenças infecciosas, inclui-se a educação em saúde. Das doenças infecciosas, as parasitoses apresentam elevadas prevalências mundiais, principalmente, nos países em desenvolvimento como o Brasil (NEVES et al., 2011; BRASIL, 2016).

A educação em saúde constitui uma ferramenta importante para a formação de crianças e jovens, visando à prevenção de inúmeros agravos à saúde e a extensão universitária permite a interação entre a universidade e a sociedade contribuindo para a formação de profissionais com responsabilidade social (SCHALL; STRUCHINER, 1999; OLIVEIRA; ALMEIDA JUNIOR, 2015). Essa proposta de extensão teve como público-alvo (crianças da educação infantil e ensino fundamental) e jovens, do ensino médio. Atividades sobre as enteroparasitoses e pediculose (ectoparasitose) foram desenvolvidas junto às crianças, pois são mais susceptíveis a essas afecções, devido à imaturidade do sistema imunológico associada à deficiência dos hábitos de higiene. Considerando que os jovens são ou estão próximos a se tornarem sexualmente ativos, optou-se por atividades sobre a toxoplasmose que apresenta transmissão congênita, importante causa de abortos ou má-formação fetal; e a tricomoníase, que constitui a infecção sexualmente transmitida mais frequente no mundo. 
Dentre as causas de morbidade e mortalidade humana incluem-se as enteroparasitoses, que são consideradas um importante problema de saúde pública; são causadas por helmintos e/ou protozoários, cujas formas evolutivas infectam o sistema gastrointestinal humano em todas ou alguma fase do ciclo evolutivo do parasita. A prevalência de parasitoses intestinais, nos países em desenvolvimento, é elevada devido às más condições de higiene alimentar e pessoal, associadas com carência ou ausência de infraestrutura em saneamento básico (ANGELUCI $e t$ al., 2013; DUFLOTH et al., 2013). As enteroparasitoses clinicamente podem ser assintomáticas, sintomáticas leves (diarreia, dores abdominais, vômitos, irritabilidade e perda de peso) e sintomáticas graves (anemia e outras complicações), principalmente, em pacientes que estão desnutridos ou imunossuprimidos (NEVES et al., 2016; ANDRADE et al., 2015; ALEMAYEHU et al. 2017).

A pediculose, uma ectoparasitose, com elevada prevalência na faixa etária infantil e escolar, atingindo todas as classes sociais; devido ao parasitismo exercido por Pediculus (humanus) capitis na cabeça, popularmente conhecido como piolho. A patogenia da pediculose inclui anemia decorrente do hematofagismo exercido pelo parasito (nos estádios de macho, fêmea e ninfa) e lesões pruriginosas no couro cabeludo devido à coceira, podendo levar a complicações como: infecções secundárias: bacterianas e micoses. A principal via de transmissão da pediculose é o contato direto (GABANI; MAEBARA; PIMENTAFERRARI, 2010).

Os protozoários Toxoplasma gondii, agente etiológico da toxoplasmose e Trichomonas vaginalis, agente etiológico da tricomoníase, apresentam distribuição mundial. No ciclo de vida de T. gondii, os felinos como os gatos domésticos constituem os hospedeiros definitivos, enquanto o homem, outros mamíferos e as aves são hospedeiros intermediários. Os fatores de risco para a toxoplasmose inclui a ingestão de carne malcozida ou crua de animais infectados com o estágio de cistos, de leite não pasteurizado contendo o estágio taquizoíta do parasito, de alimentos ou água contaminada por oocistos de T. gondii provenientes das fezes de felinos infectados; transmissão congênita; transfusão sanguínea ou transplante de órgãos provenientes de doador infectado pelo parasito (LAGO et al., 2010; AGUIRRE et al., 2019). A toxoplasmose pode se manifestar através da corioretinite em adultos ou ser consequência de uma infecção congênita pelo parasito. Sendo a última, importante causa de abortos e má formação fetal (BISSATI et al., 2018). 
O parasito T. vaginalis apresenta ciclo de vida monoxênico, cujo habitat é o trato urogenital humano e a transmissão da infecção ocorre por contato sexual, sendo considerada a doença sexualmente transmissível não viral mais comum no mundo (MACIEL; TASCA; DE CARLI, 2004; WHO, 2012).

A transversalidade por meio da educação em saúde pode fornecer possibilidades para o público-alvo tomar consciência das ações em detrimento de sua saúde e assim, será possível agir de forma autônoma em benefício próprio (MARINHO; SILVA; FERREIRA, 2015). As diferentes metodologias utilizadas nesse projeto (palestras, contar estórias, teatro de fantoches e jogo de memória) permitiram interações com diferentes faixas etárias dos estudantes, de modo a proporcionar melhor aprendizagem dos conteúdos trabalhados. No caso das crianças da educação infantil, o trabalho com as linguagens corporal e plástica possibilitam a participação nas situações abordadas e o estabelecimento de uma relação significativa com o cotidiano (MORAIS; ALBUQUERQUE; BRANDÃO, 2016). A atuação efetiva das crianças no controle de parasitoses tem sido proposta nos trabalhos de educação em saúde, permitindo a sensibilização sobre esse problema e a formação de um cidadão capaz de criar cenários alternativos (TOSCANI, 2007). Os objetivos desse projeto foram realizar atividades de educação em saúde sobre as parasitoses humanas nas escolas públicas do Município de Jataí, Goiás, e contribuir para a interação de graduandos em Biomedicina e Enfermagem com a comunidade local.

\section{PROCEDIMENTOS METODOLÓGICOS}

O projeto de Extensão "Educação em Saúde: parasitoses humanas" foi cadastrado e desenvolveu suas atividades no período de 20/11/2008 a 12/07/2011. Participaram do projeto: duas docentes do curso de Biomedicina e discentes dos cursos de graduação em Biomedicina e Enfermagem da Universidade Federal de Goiás, Regional Jataí.

\section{Participação das escolas públicas e o público alvo}

O município de Jataí possuía em 2008, 27 escolas municipais (sendo 19 urbanas) e 11 estaduais. A escolha das escolas participantes, de acordo com a capacidade de trabalho da equipe do projeto, ocorreu mediante sorteio de nove escolas urbanas. Destas, quatro são estaduais e cinco municipais. As visitas nas escolas ocorreram no período de novembro de 
2008 a janeiro de 2009, o projeto foi apresentado aos diretores e professores de educação infantil, de Ciências (ensino fundamental) e Biologia (ensino médio). Cada escola representada pela direção teve autonomia para aceitar ou recusar o desenvolvimento das atividades previstas e todas as sorteadas aceitaram. O projeto foi desenvolvido com anuência da Secretaria Municipal de Educação e da Subsecretaria Estadual de Educação de Jataí-GO.

\section{Planejamento de atividades de educação em saúde}

As atividades de planejamento sobre as temáticas: parasitoses intestinais, pediculose, toxoplasmose e tricomoníase foram realizadas nas dependências da REJ-UFG, unidade Jatobá. Os acadêmicos de Biomedicina e Enfermagem, sob a orientação das docentes do projeto, realizaram revisões bibliográficas em livros didáticos e artigos científicos que abordavam os temas propostos e elaboraram palestras e montagem de materiais pedagógicos (cartazes, transparências, slides e jogos). Os acadêmicos desenvolveram um jogo da memória com diferentes formas parasitárias e medidas de prevenção contra parasitos intestinais.

As palestras sobre parasitoses intestinais foram ministradas a estudantes do sexto ao nono ano do ensino fundamental, houve o cuidado de empregar-se linguagem apropriada, visando melhor compreensão dos conteúdos. Para as atividades sobre pediculose, desenvolvidas junto às turmas de educação infantil e do primeiro ao quinto ano do ensino fundamental foi utilizada linguagem lúdica por meio de fantoches e técnica de contar estórias. As atividades sobre toxoplasmose e tricomoníase foram ministradas somente aos jovens com utilização de data show para realizar as palestras e linguagem acessível; considerando os termos científicos estudados no ensino médio na área de Ciências Biológicas. E cartazes foram elaborados com ilustrações do ciclo biológico dos parasitos e medidas profiláticas para a interrupção da transmissão das doenças relacionadas.

\section{Execução das atividades de educação em saúde}

As ações interativas com os estudantes nas escolas públicas, propostas pelo projeto, foram executadas em salas de aulas ou auditórios, sempre no horário das aulas e com a presença dos professores responsáveis pelas turmas. As palestras sobre parasitos intestinais foram apresentadas pelos acadêmicos da graduação, utilizando computador e data show; contendo ilustrações da morfologia, o ciclo de vida, as formas de transmissão, diagnóstico e medidas 
profiláticas, com duração média de 20 minutos de exposição, acrescido de 10 minutos para esclarecimentos de dúvidas. Após a palestra, foi exibido um filme documentário, breve, sobre os parasitos citados pela palestrante. Em seguida, os estudantes participaram de um jogo da memória que abordava o mesmo tema, em grupos de 4 a 5 . Esse jogo teve a duração de 15 a 20 minutos e ao final da atividade foram distribuídos certificados de desempenho excelente aos grupos.

As atividades sobre pediculose foram planejadas de forma lúdica: peça teatral com fantoches e a técnica de contar estórias infantis; com duração média de 20 minutos e abordou-se a morfologia dos piolhos, o ciclo de vida, formas de transmissão e as medidas de profilaxia.

As palestras sobre Toxoplasmose e Tricomoníase foram ministradas aos jovens, do ensino médio, com duração média de 30 minutos, em que graduandos da UFG-REJ apresentaram um único tema (por sessão): toxoplasmose ou tricomoníase, abordando a morfologia do parasito, o ciclo de vida, as formas de transmissão, o diagnóstico e as medidas profiláticas. Ao término de cada palestra, as dúvidas relacionadas aos temas foram esclarecidas.

\section{A avaliação do projeto}

As avaliações das ações desenvolvidas nas escolas públicas foram realizadas pelo acompanhamento contínuo do registro do número de pessoas (graduandos e da educação básica) envolvidas no projeto e observação do interesse e participação dos estudantes das escolas nas atividades propostas. Esses indicadores foram complementados pela aplicação de uma pesquisa de opinião junto aos diretores das escolas sobre as ações desenvolvidas, com as seguintes questões: 1) o projeto "Educação em saúde: parasitoses humanas" cumpriu o cronograma de atividades apresentado à direção da escola?; e 2) considerando os níveis de satisfação de 0 a 5 (sendo $0=$ muito ruim, 1= ruim, 2=razoável, 3= bom, 4=muito bom e 5= ótimo) com como você avalia as atividades do projeto "Educação em saúde: parasitoses humanas"?

\section{RESULTADOS}

O presente projeto de extensão foi realizado em quatro escolas estaduais e cinco municipais e atendeu ao público alvo de 593 alunos, sendo 305 da educação infantil e do ensino fundamental (escolas municipais) e 288 do ensino médio (escolas estaduais) (Tabela 1). Esses 
estudantes representaram fatores multiplicadores do conhecimento adquirido, por meio das ações de educação em saúde, no meio social onde passam parte do seu tempo diário exercendo a cidadania e o direito à informação sobre saúde. Houve participação ativa das crianças e jovens, em todas as atividades desenvolvidas, demonstrada por meio de interações com os graduandos, relatos de fatos vivenciados no cotidiano e relacionados aos temas abordados. Além de esclarecimentos de dúvidas sobre os conteúdos das palestras, jogos, estórias e material ilustrativo.

Tabela 1 - Distribuição dos 593 estudantes por turmas e escolas atendidas pelas atividades sobre parasitoses humanas, no período de julho de 2009 a julho de 2011

\begin{tabular}{|c|c|c|c|}
\hline Escola Pública & $\begin{array}{l}\text { Número } \\
\text { de turmas }\end{array}$ & $\begin{array}{l}\text { Número de } \\
\text { alunos }\end{array}$ & $\begin{array}{c}\text { Pesquisa de } \\
\text { opinião* } \\
\text { (Nota de } 0 \text { a } 5 \text { ) }\end{array}$ \\
\hline
\end{tabular}

\section{Rede Estadual}

Marcondes de Godoy $2 \quad 65$

5

Nestório Ribeiro

2

70

5

Serafim de Carvalho

3

90

5

José Feliciano Ferreira

2

63

4

\section{Rede Municipal}

Ubaldina Ribeiro

1

Professor João Justino de Oliveira

Infantil Pedacinho do Céu

David Ferreira 2

133

João Justino de Oliveira 2

266

4

$2 \quad 54$

\begin{tabular}{llll}
\hline Total & 18 & 593 & Média=4,8 \\
\hline somente os diretores das escolas avaliaram. & &
\end{tabular}

somente os diretores das escolas avaliaram.

Fonte: As autoras (2019).

As atividades, planejadas e executadas, foram avaliadas pelos diretores das nove escolas que deram nota 4 ou 5, demonstrando a ótima aceitação dessa proposta, a responsabilidade e comprometimento dos graduandos que executaram as mesmas com entusiasmo.

A opção de contar estórias e o teatro de fantoches proporcionou melhor comunicação com as crianças da educação infantil. 


\section{CONSIDERAÇÕES FINAIS}

Esse projeto teve ótima aceitação pelos diretores das escolas atendidas e as atividades utilizaram a educação para a promoção de medidas de prevenção e controle de doenças parasitárias que afetam a população, principalmente, crianças e jovens; colaborou para a formação de biomédicos e acadêmicos dos cursos de Biomedicina e Enfermagem, pois propiciou interações com a comunidade local, estimulando a responsabilidade social por meio da prática da educação em saúde, tornando-se cidadãos mais conscientes do seu papel na sociedade. Houve participação ativa do público-alvo, por meio de interações com os conteúdos e acadêmicos da graduação, colaborando na formação de cidadãos mais conscientes da realidade social onde estão inseridos. Além disso, os dados desse projeto podem contribuir para o desenvolvimento de outras ações de promoção em saúde sobre o tema parasitoses humanas no município de Jataí ou em outras localidades.

\section{REFERÊNCIAS}

ALEMAYEHU, B. et al. Epidemiology of intestinal helminthiasis among school children with emphasis on Schistosoma mansoni infection in Wolaita zone, Southern Ethiopia. Biomed Central, Londres, v. 17, n. 587, p. 2-10, 2017. Doi: 10.1186/s12889-017-4499-x.

AGUIRRE, A. A. et al. The one health approach to toxoplasmosis: epidemiology, control and prevention strategies. EcoHealth, New York, NY, v. 16, n. 2, p. 378-90, 2019. Doi: 10.1007/s10393-019-01405-7.

ANDRADE, A. M. et al. Intestinal obstruction in a 3-year-old girl by Ascaris lumbricoides infestation: case report and review of the literature. Medicine, Baltimore, v. 94, n. 16, p. 1-3, 2015. Doi: 10.1097/MD.0000000000000655.

ANGELUCI, C. H. G. et al. Avaliação da prevalência de parasitoses intestinais em escolares do Município de Formosa-GO. Sinergia, São Paulo, v. 14, n. 3, p. 227-232, 2013.

BISSATI, K. E. et al. Global initiative for congenital toxoplasmosis: an observational and international comparative clinical analysis. Emerging Microbes and Infections. Philadelphia, v.7, n. 165, p. 1-14, 2018. Doi: 10.1038/s41426-018-0164-4.

BRASIL. Ministério da Saúde. Secretaria de Vigilância em Saúde. Coordenação-Geral de Desenvolvimento da Epidemiologia em Serviços. Guia de Vigilância em Saúde. Brasília, DF: MS, 2016.

DUFLOTH, D. B. et al. Pesquisa sobre a contaminação de hortaliças por ovos e larvas de nematódeos e cistos de protozoários como método de estudo. Revista de Patologia Tropical, Goiânia, v. 42, n. 4, p. 443-454, 2013. Doi: 10.5216/rpt.v42i4.27923. 
GABANI, F. L.; MAEBARA, C. M. L.; PIMENTA-FERRARI, R. A. Pediculose nos centros de educação infantil: conhecimentos e práticas dos trabalhadores. Escola Anna Nery Revista Enfermagem, Rio de Janeiro, v. 14, n. 2, p. 309-371, 2010. Doi: 10.1590/S141481452010000200014 .

LAGO, M. L.; PITREZ, M. C. Toxoplasmose, interdicisplinaridade e geografia. Scientia Medica, Porto Alegre, v. 20, n. 1, p. 3-4, 2010. Doi: 10.15448/1980-6108.2010.1.6949.

MACIEL, G. P.; TASCA, T.; De CARLI, G. A. Aspectos clínicos, patogênese e diagnóstico de T. vaginalis. Jornal Brasileiro de Patologia Médica e Laboratorial, Rio de Janeiro, v. 40, n. 3, p. 152-160, 2004. Doi: 10.1590/S1676-24442004000300005.

MARINHO, J. C. B.; SILVA, J. A.; FERREIRA, M. A educação em saúde como proposta transversal: analisando os Parâmetros Curriculares Nacionais e algumas concepções docentes. História, Ciências, Saúde, Rio de Janeiro, v. 22, n. 2, p. 429-443, 2015. Doi: 10.1590/S010459702014005000025.

MORAis, A. G.; AlBUQUERQUE, E. B. C.; BRANDÃO, A. C. P. A. Refletindo sobre a língua escrita e sobre sua notação no final da educação infantil. Revista Brasileira de Estudos Pedagógicos, Brasília, v. 97, n. 247, p. 519-533, 2016. Doi: 10.1590/s2176$6681 / 277833582$.

NEVES, D. P. et al. Parasitologia humana. 13. ed. São Paulo: Atheneu, 2016.

OLIVEIRA, F. L. B. de; ALMEIDA JUNIOR, J. J. de. Motivações de acadêmicos de enfermagem atuantes em projetos de extensão universitária: a experiência da Faculdade Ciências da Saúde do TRAIRI/UFRN. Espaço para a Saúde, Londrina, v. 16, n. 1, p. 40- 47, 2015. Doi: 10.22421/1517-7130.2015v16n1p40.

SCHALL V. T., STRUCHINER, M. Educação em saúde: novas perspectivas. Cadernos de Saúde Pública, Rio de Janeiro, v.15, supl. 2, 1999. Doi: 10.1590/S0102311X1999000600001.

TOSCANI, N. V. et al. Desenvolvimento e análise de jogo educativo para crianças visando à prevenção de doenças parasitológicas. Interface: Comunicação, Saúde e Educação. Botucatu, v. 11, n. 22, p. 281-294, 2007. Doi: 10.1590/S1414-32832007000200008.

UNITED NATIONS (ONU). Millennium development goal 8: taking stock of the global partnershipfor evelopment. MDG Gap Task Force. Report 2015.

WORLD HEALTH ORGANIZATION. Global incidence and prevalence of selected curable sexually transmitted infections - 2008. Geneva: WHO, 2012.

Submetido em 18 de julho de 2019.

Aprovado em 11 de outubro de 2019. 